\title{
Cephalometric Floating Norms for Czech Adults
}

\author{
Řeháček A., Janega M., Hofmanová P., Dostálová T. \\ Department of Paediatric Stomatology, Second Faculty of Medicine, Charles \\ University in Prague and University Hospital Motol, Prague, Czech Republic \\ Received December 6, 2011; Accepted October 10, 2012.
}

Key words: Lateral cephalograms - Cephalometric norms - Hasund harmony schema

\begin{abstract}
The purpose of this study was to establish floating cephalometric norms for the description of the individual skeletal pattern in Czech adults. Floating norms provide a method of analysis that uses the variability of the associations among suitable cephalometric measures, on the basis of the regression model combining both sagittal and vertical skeletal parameters. Harmony box is a simple and useful tool for diagnostics of orthodontic anomalies according to individual cephalometric norms. 118 subjects, 53 male and 65 female, from Czech population were selected. The method of multiple regression analysis was used to determine interdependence among five cephalometric variables of the sample. Linear regression equations with corresponding $r^{2}$ and standard error of the estimate (SE) were then illustrated as the harmony box. The results construct a harmony box based on correlated cephalometric variables. The multiple regression analysis of the data is graphically illustrated as a harmony schema which divides harmony box in three zones according to the type of the face - prognathic, orthognathic and retrognathic. The cephalometric floating norms describing the individual craniofacial pattern among Czech adults were established based on five correlated variables in the form of a harmony box.
\end{abstract}

This study was supported by grant GAUK No. 89008.

Mailing Address: MDDr. Adam Řeháček, Department of Paediatric Stomatology, Second Faculty of Medicine, Charles University in Prague and University Hospital Motol,V úvalu 84, 15006 Prague 5, Czech Republic; e-mail: rehacek.adam@email.cz 


\section{Introduction}

The need for lateral cephalometric analysis in orthodontic diagnosis and treatment planning is well established. The goal of cephalometric analysis is to estimate the relationship, vertically and horizontally of the jaws to the cranial base and to each other, the relationships of the teeth to their supporting bone, and the effect of the teeth on the profile (Wahl, 2006). The principle is that the radiographic measurements of each patient are compared with normative values. After Broadbendt (1931) and Hofrath (1931) who simultaneously published methods used to obtain standardized head radiographs in 1931, numerous cephalometric analyses related to standardized norms were developed. Orthodontists use the values of those measurements or norms for their diagnosis, treatment, and assessment of orthodontic treatment outcomes (Proffit et al., 1992; Tahir et al., 1997; Alcalde et al., 1998).

The criteria of the samples for the cephalometric norms were estimated for untreated subjects of same ethnic group with well balanced face and normal occlusion. These measurements with their standard deviations provided guidelines for orthodontic diagnosis and treatment planning. The conventional cephalometric analysis doesn't take into account the possible interdependence among the cephalometric variables and compare each cephalometric value of the patient with an appropriate normative value separately. However, the appropriate application

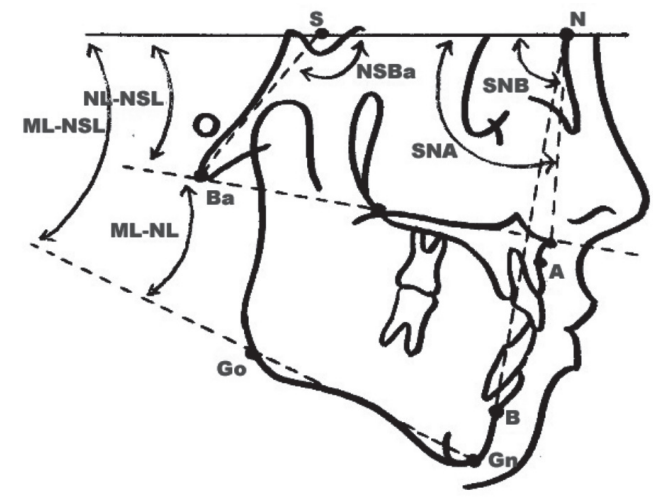

Figure 1 - Cephalometric points with corresponding angular variables.

Figure 2 - Segner-Hasund harmony box.

\begin{tabular}{|c|c|c|c|c|c|c|}
\hline & SNA & NL-NSL & NSBa & ML-NSL & SNB & ML-NL \\
\hline 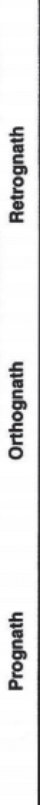 & $\begin{array}{l}62 \\
63 \\
64 \\
65 \\
66 \\
67 \\
68 \\
69 \\
70 \\
71 \\
72 \\
73 \\
74 \\
75 \\
76 \\
77 \\
78 \\
79 \\
80 \\
81 \\
82 \\
83 \\
84 \\
85 \\
86 \\
87 \\
88 \\
89 \\
90 \\
91 \\
92 \\
93 \\
94 \\
95 \\
96 \\
97 \\
98 \\
99 \\
100 \\
101 \\
102 \\
103\end{array}$ & $\begin{array}{c}14 \\
\bullet \\
13 \\
\bullet \\
12 \\
\bullet \\
11 \\
\bullet \\
10 \\
\bullet \\
9 \\
\bullet \\
8 \\
\bullet \\
7 \\
\bullet \\
6 \\
\bullet \\
5 \\
\bullet \\
4 \\
\bullet \\
3 \\
\bullet \\
2 \\
\bullet \\
1\end{array}$ & $\begin{array}{l}131 \\
130 \\
129 \\
128 \\
127 \\
126 \\
125\end{array}$ & $\begin{array}{l}43 \\
42 \\
41 \\
40 \\
39 \\
38 \\
37 \\
36 \\
35 \\
34 \\
39 \\
32 \\
31 \\
30 \\
29 \\
28 \\
27 \\
26 \\
25 \\
24 \\
23 \\
22 \\
21 \\
20 \\
20 \\
19 \\
18 \\
17 \\
16 \\
15 \\
5\end{array}$ & $\begin{array}{l}64 \\
65 \\
66 \\
67 \\
68 \\
62 \\
70 \\
72 \\
72 \\
73 \\
73 \\
74 \\
75 \\
76\end{array}$ & $\begin{array}{c}28 \\
\bullet \\
27 \\
\bullet \\
26 \\
\bullet \\
25 \\
\bullet \\
24 \\
\bullet \\
23 \\
\bullet \\
22 \\
\bullet \\
21 \\
\bullet \\
20 \\
\bullet \\
19 \\
\bullet \\
18 \\
\bullet \\
17 \\
\bullet \\
16 \\
\bullet \\
15 \\
\bullet \\
14 \\
\bullet \\
13 \\
\bullet\end{array}$ \\
\hline
\end{tabular}


of any cephalometric analysis must be used with norms derived from populations similar to the orthodontic patients with regard to ethnic group, gender, and age (Athanasiou, 1997). The cephalometric norms don't have to represent a real situation in craniofacial skeletal system but they are necessary to evaluate a measured diagnostic value. Solow (1966) in his study "The pattern of the craniofacial associations" demonstrated significant correlations between sagittal and vertical cephalometric variables, leading to the concept of "craniofacial pattern". This implies that even though all cephalometric values of a patient lie beyond one standard deviation (SD) from the population, they still may be considered acceptable if they maintain a certain correlation with each other (Sevilla-Naranjilla and Rudzki-Janson, 2009). Hasund et al. (1974) first described combinations of acceptable values for different facial types. Finally, a comprehensive analysis for the assessment of individual craniofacial patterns was performed by Segner (1989) and Segner and Hasund (1994), who constructed floating norms for the description of sagittal and vertical skeletal relationships in a sample of European adults. The method is based on the correlations among the following craniofacial measurements: SNA, SNB, NL-NSL, ML-NSL, and NSBa (Figure 1). Interdependence between two cephalometric variables is described by linear correlation coefficient " $r$ " (Segner and Hasund, 1994).

The concept of harmony box was established by Segner (1989) and Segner and Hasund (1994) and at present is widely used its improved form as a Segner-Hasund harmony box (Segner and Hasund, 1998) (Figure 2). The linear regression analysis was used to construct a harmony schema, which contained the cephalometric floating norms of the five correlated variables. The harmony box is divided into three zones - retrognathic, orthognathic, and prognathic zones - depending on the ANB value of the subject. Angle ANB represents the anterioposterior relationship of the maxilla with the mandible (Zwemer, 1998).

The cephalometric variables are illustrated graphically and their values are arranged in five columns. A horizontal line connecting the values of these cephalometric variables inside the box represents the harmony line of the subject. A straight horizontal line suggests that the face is harmonious, and the facial type is determined according to the zone where the cephalometric values of the subject fall. For every horizontal harmony line, a range of accepted variability is allowed, which is derived from the standard error of the estimate (SE) of the multiple regression analysis and is represented by the harmony schema (Sevilla-Naranjilla and Rudzki-Janson, 2009).

The harmony schema varies by the different population group. When the cephalometric values of the subject lie inside the harmony schema for appropriate population group (the value maintains a certain correlation with each other according to SD) the skeletal pattern of the subject may be considered harmonious. By this means the harmony schema determines a facial type. Any value that lies outside the schema is a parameter that causes disharmony to the face. The face is considered to be disharmonious (Sevilla-Naranjilla and Rudzki-Janson, 
2009). The floating norms are nowadays a valuable diagnostic tool in orthodontics. In 1998 Franchi, Baccetti, and McNamara established a floating norms for North American adults. Ngarmprasertchai (2002) and Mahaini (2005) provided floating norms for Thais and Syrians. Tollaro and co-workers (1996) established floating norms for the southern European children with full deciduous dentition. In 2009 Sevilla-Naranjilla and Rudzki-Janson presented floating norms for Filipinos. The purpose of this study was to establish floating norms for the description of the individual skeletal pattern in Czech adults.

\section{Material and Methods}

The sample comprised Caucasian 118 subjects aged 18-45 (mean 26.3 years, SD 7.2 years), 53 males (mean age 26.1 years, SD 8.3 years) and 65 females (mean age 26.4 years, SD 6.1 years) from Czech Republic. The selection criteria for the study were: well-balanced profile, ideal or near-ideal occlusion (Class I molar relationship, Class I canine relationship) and no previous orthodontic treatment. Lateral cephalograms were taken in centric occlusion with lips in repose and natural head position.

Cephalometric points were digitized and the five cephalometric angular measurements were obtained using the PC Dent program (version 3.0.2). These angular measurements were: SNA (maxillary prognathism), SNB (mandibular prognathism), NL-NSL (maxillary inclination relative to the cranial base), ML-NSL (mandibular inclination relative to the cranial base), and NSBa (cranial base angle). The method error was determined by retracing and measuring 10 randomly selected radiographs again, which generated an average error of less than 0.4 degree.

\section{Statistical analysis}

The statistical examination for the measured data comprised: calculation of Pearson's correlation coefficients, bivariate linear regression analysis and multiple linear regression analysis.

\section{Results}

Table 1 shows descriptive statistics for all of the five angular measurements with relevant standard deviation (SD). Table 2 describes correlation coefficients (r) between the five cephalometric variables. Linear regressions with corresponding $r^{2}$ and standard error of the estimate (SE) of Czech adults are shown in Table 3 and illustrated as the harmony box in Figure 3. The multiple correlation coefficients $(r)$, the adjusted $r^{2}$ and the standard error of the estimate when one of the variables SNA, SNB, NL-NSL, ML-NSL, NSBa is predicted from the other four by means of multiple regression analysis is graphically illustrated as harmony schema for Czech adults in Figure 4. The mean values of five variables inside the harmony schema form a harmony line (Figure 5). 
Table 1 - Descriptive statistics $(n=118)$

\begin{tabular}{lrrrr}
\hline \multicolumn{1}{c}{ Variables } & Mean & SD & Min & Max \\
\hline SNA & 81.96 & 3.15 & 73.30 & 88.50 \\
NL-NSL & 7.60 & 2.89 & 0.80 & 16.10 \\
NSBa & 130.64 & 4.35 & 118.60 & 143.30 \\
ML-NSL & 29.74 & 4.71 & 13.60 & 40.90 \\
SNB & 79.72 & 3.28 & 70.90 & 86.90 \\
ML-NL & 22.12 & 4.39 & 10.50 & 32.20 \\
\hline
\end{tabular}

Table 2 - Linear correlation coefficients $(r)$ between SNA, NL-NSL, NSBa, ML-NSL, and SNB of Czech adults $(n=118)$

\begin{tabular}{lccccc}
\hline \multicolumn{1}{c}{ Variables } & SNA & NL-NSL & NSBa & ML-NSL & SNB \\
\hline SNA & 1 & & & & \\
NL-NSL & $-0.45^{*}$ & 1 & & & \\
NSBa & $-0.45^{*}$ & $0.4^{* *}$ & 1 & & \\
ML-NSL & $-0.37^{*}$ & $0.42^{* *}$ & $0.21^{* *}$ & 1 & 1 \\
SNB & $0.84^{*}$ & $-0.55^{* *}$ & $-0.42^{* *}$ & $-0.56^{* *}$ & 1 \\
\hline
\end{tabular}

$* \mathrm{P}<0.01 ; * * \mathrm{P}<0.05$

Table 3 - Linear regressions with corresponding $r^{2}$ and standard error of the estimate (SE) of Czech adults $(n=118)$

\begin{tabular}{llll}
\hline \multicolumn{1}{c}{ Variables } & Regression equation & $\mathrm{r}^{2}$ & $\mathrm{SE}$ \\
\hline NL-NSL & $=-0.411 \times \mathrm{SNA}+41.308$ & 0.20 & 2.60 \\
$\mathrm{NSBa}$ & $=-0.625 \times \mathrm{SNA}+181.83$ & 0.20 & 3.90 \\
ML-NSL & $=-0.547 \times \mathrm{SNA}+74.547$ & 0.13 & 4.40 \\
SNB & $=0.876 \times \mathrm{SNA}+7.965$ & 0.71 & 1.78 \\
SNA & $=-0.327 \times \mathrm{NSBa}+124.67$ & 0.20 & 2.82 \\
SNB & $=-0.3171 \times \mathrm{NSBa}+121.14$ & 0.18 & 2.99 \\
ML-NSL & $=-0.804 \times \mathrm{SNB}+93.795$ & 0.31 & 3.92 \\
\hline
\end{tabular}




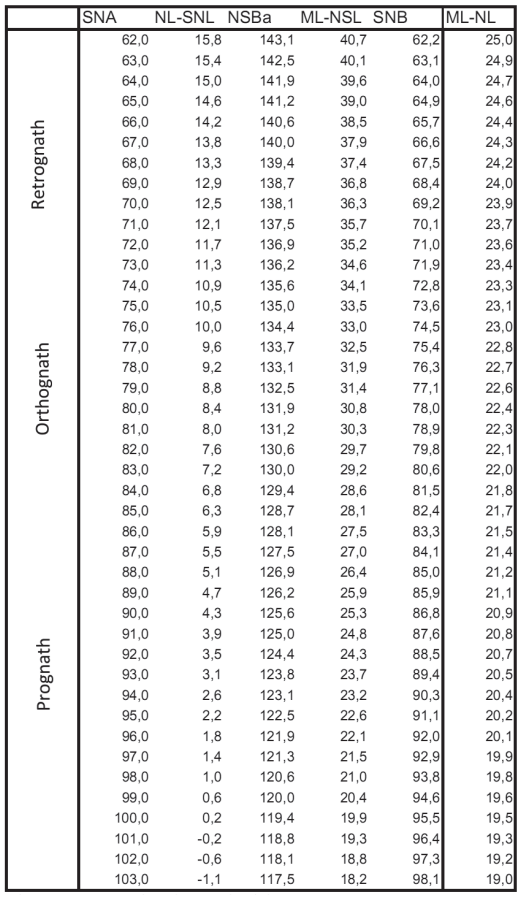

Figure 3 - Harmony box for Czech adults.

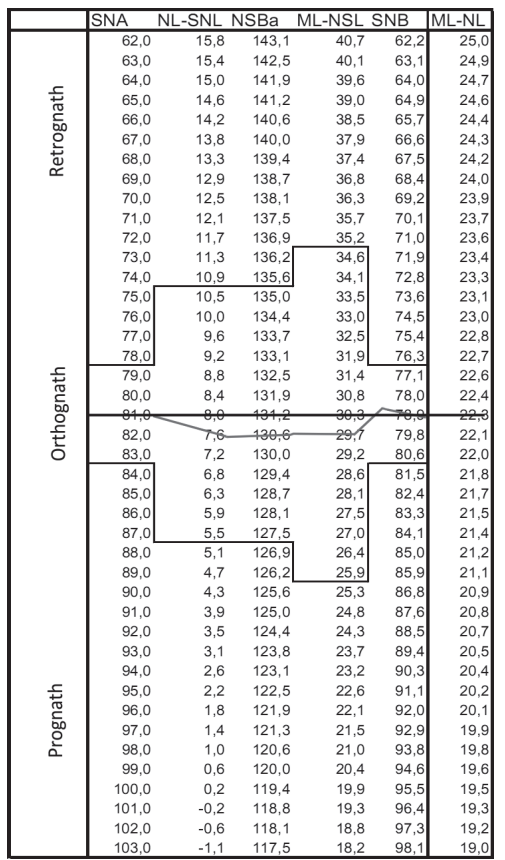

Figure 5 - Harmonious combinations.

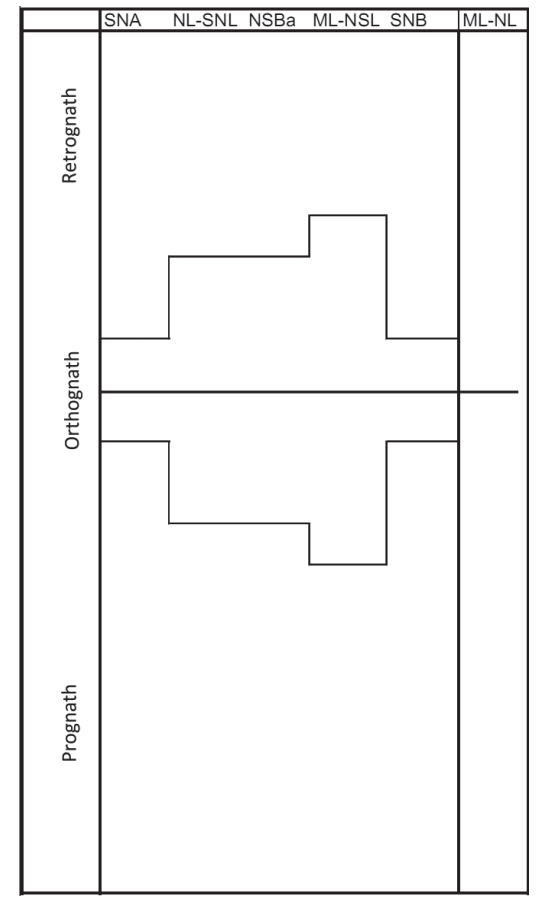

Figure 4 - Harmony schema for Czech adults.

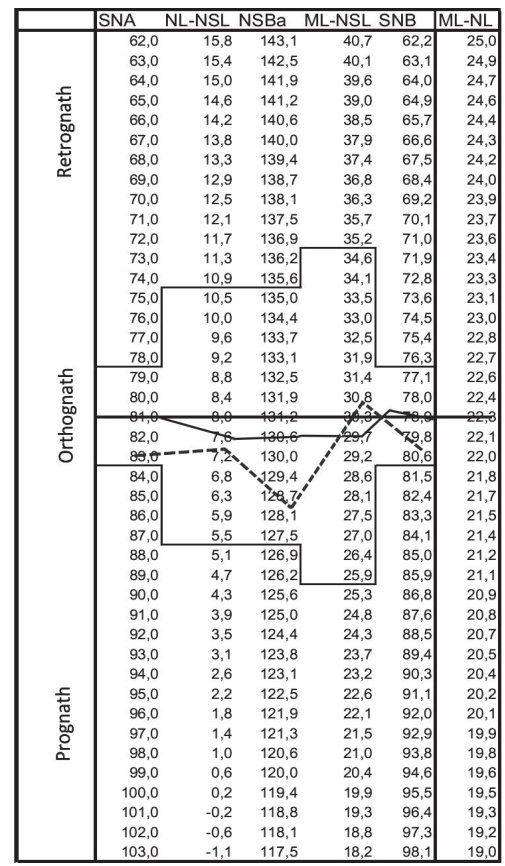

Figure 6 - Comparison Czech adults (connected line) with North American adults (dashed line). 


\section{Discussion}

The Segner-Hasund harmony box is a useful auxiliary diagnostic tool to determine craniofacial anomalies in orthodontics and maxillofacial surgery. The conventional cephalometric analysis compares the cephalometric measurements of the individual patient with the cephalometric norms of corresponding ethnic or population group. The craniofacial skeleton is not then considered as one unit with certain harmonic rules. As long as the cephalometric measurements of the subject lie inside the harmony schema (despite their absolute values) the skeletal pattern may be considered harmonious. A harmonious combination from a correlation point of view would not necessarily require the values to lie on a perfectly straight horizontal line (Segner, 1989).

According to three zones inside the box (prognathic, ortognathic and retrognathic) a type of face may be described as prognathic but still harmonious, orthognathic and harmonious and retrognathic and harmonious.

The harmony schema is constructed by computing the SE when one of the cephalometric variables is predicted from the other four by multiple regression analysis (Table 3). It represents the degree of variability allowed among the five correlated cephalometric measurements for describing a harmonious face. It could be shifted on the different zones of the harmony box to include all five cephalometric variables of a subject (Sevilla-Naranjilla and Rudzki-Janson, 2009). The individual floating norms are then different for every patient considering his individual morphology.

Figure 6 shows comparison of mean cephalometric values of the five correlated variables among the North American Caucasian adults. All variables lie inside the harmony schema for Czech adults and in the orthognathic zone of harmony box. The line connecting the values of North Americans is shifted downward. This mean that the North Americans have more prognathic type of face in comparison with Czech adults but their craniofacial morphology is not largely different.

\section{Conclusion}

Cephalometric floating norms describing individual skeletal pattern based on correlation of five cephalometric variables are established for the Czech Caucasian adults. Results are graphically illustrated as a Hasund harmony box and harmony schema.

\section{References}

Alcalde, R. E., Jinno, T., Pogrel, M., Matsumura, T. (1998) Cephalometric norms in Japanese adults. J. Oral Maxillofac. Surg. 56(2), 129-134.

Athanasiou, A. (1997) Orthodontic Cephalometry. Mosby-Wolfe, London.

Broadbent, B. H. (1931) A new X-ray technique and its application to orthodontia. Angle Orthod. 1, 45-66.

Franchi, L., Baccetti, T., McNamara, J. A. Jr. (1998) Cephalometric floating norms for North American adults.

Angle Orthod. 68, 497-502. 
Hasund, A., Böe, O. E., Jenatsche, F., Nordeval, K., Thunold, K., Wisth, P. J. (1974) Clinical Cephalometry for the Bergen Technique. University of Bergen, Bergen.

Hofrath, H. (1931) Bedeutung der Röntgenfern und Abstands Aufnahme für die Diagnostik der Kieferanomalien. Fortschr. Orthod. 1, 231-258.

Mahaini, L. (2005) Kraniofaziale Strukturen syrischer und deutscher Probanden - Eine kephalometrische Studie (Med. Dissertation). Ludwig Maximilian University of Munich, Munich, Germany.

Ngarmprasertchai, S. (2002) Vergleich der dento-kraniofazialen Morphologie zweier ethnischer Gruppen mit eugnathem Gebiss im Fernröntgenseitenbild (Med. Dissertation). Ludwig Maximilian University of Munich, Munich, Germany.

Proffit, W. R., Phillips, C., Douvartzidis, N. (1992) A comparison of outcomes of orthodontic and surgicalorthodontic treatment of Class II malocclusion in adults. Am. J. Orthod. Dentofacial Orthop. 101(6), 556-565.

Segner, D. (1989) Floating norms as a means to describe individual skeletal patterns. Eur. J. Orthod. 11, 214-220.

Segner, D., Hasund, A. (1994) Individualisierte Kephalometrie. Franklin Printing and Publishing House Ltd., Hamburg.

Segner, D., Hasund, A. (1998) Individualisierte Kephalometrie, $3^{\text {rd }}$ Ed. Segner Verlag and Vertrieb, Hamburg.

Sevilla-Naranjilla, M. A., Rudzki-Janson, I. (2009) Cephalometric floating norms as a guide toward a harmonious individual craniofacial pattern among Filipinos. Angle Orthod. 79(6), 1162-1168.

Solow, B. (1966) The pattern of the craniofacial associations: a morphological and methodological correlation and factor analysis study on young adults. Acta Odontol. Scand. 24 (Suppl. 46).

Tahir, E., Sadowsky, C., Schneider, B. J. (1997) An assessment of treatment outcome in American Board of Orthodontics cases. Am. J. Orthod. Dentofacial Orthop. 111(3), 335-342.

Tollaro, I., Baccetti, T., Franchi, L. (1996) Floating norms for the assessment of craniofacial pattern in the deciduous dentition. Eur. J. Orthod. 18, 359-365.

Wahl, N. (2006) Orthodontics in 3 millennia. Chapter 8: The cephalometer takes its place in the orthodontic armamentarium. Am. J. Orthod. Dentofacial Orthop. 129(4), 574-580.

Zwemer, T. J. (1998) Mosby's Dental Dictionary. Mosby, St. Louis. 